\title{
Prototyping in Glass: Two-years of Collaboration with the Corning Museum of Glass
}

\author{
GEORG RAFAILIDIS \\ University at Buffalo SUNY
}

This paper documents two years of collaboration with the Corning Museum of Glass (CMoG), where two groups of graduate architecture students lead by a team of two faculty members, were able to develop projects - architectural glass components - in consultation with glassblowing experts and the resident material scientist at CMoG, and ultimately participate in the fabrication of the prototypes at CMoG's world class glassblowing facility, GlassLab.

\section{INTRODUCTION}

This paper documents experimentations with glass to prototype architectural components as an offshoot of a research project that began in 2009 into the development of a glass block facade component filled with PCM (phase change material). While the first phase of the research, done in collaboration with the chemical company BASF, focused on empirical testing of wax PCM, the current phase focuses on glass itself, and reveals how challenging it is to work with the material in an experimental way. Working first-hand, in an experimental manner, with glass presents several challenges. Unlike materials like concrete, plaster, and even ceramics, glass can only be formed with exposure to extremely high temperatures, and requires special facilities, tools and specialized skills. This paper documents the outcome of an architectural design studio dedicated to glass in architecture, taught for two years; first-hand experimentation with glass resulted in prototypes at the architectural component scale. Research was conducted with the cooperation of the Corning Museum of Glass ( $\mathrm{Cog}$ ) and their state-of-the-art Glass Lab facilities for hot glass work. Simultaneously, work with kiln-formed glass was conducted at the university, using refractory molds and both ceramic and glass kilns.

The results of the student experiments revealed the limitations of one-off artisanal glass production techniques - both warm and hot in making prototypes that require extremely high degrees of precision.

With the Thermometric Façade we investigated the intriguing material properties of wax phase change material and developed an architectural proposal from the material specificity of wax phase change materials. Glass turned out to be an intriguing phase change material in its own right and allowed us to speculate on its' architectural potential in a material specific manner. In the following I will describe three student projects selected from twelve projects that emerged over the course of two design studios.

\section{GRADUATE DESIGN STUDIO PROJECTS:}

\section{VARIATION INSTEAD OF REPETITION IN KILN FORMED GLASS} (STUDENT TEAM: KIM SASS, STEVE SMIGIELSKI)

The first project began by tackling the challenge of creating forms that are typologically related but geometrically different. In kiln formed glass casting, molds typically produce identical forms and formal differences or aberrations between the cast pieces are seen as undesirable. The same holds true for the fabrication of aggregated building elements. Bricks, for example, should have the same dimensions to be laid as a brick wall in an efficient manner.

This project, however, looked how glass casting could lead to a family of forms which are clearly identifiable as belonging to a single formal typology, with individual, geometric variations within that typology. Trees and icicles served as precedents for this project. Although each tree is geometrically distinct, we can clearly read them all formally as trees. All trees also follow the same structural principle, although they are geometrically distinct. Icicles are also all formally different, although we identify them in a generalized category as icicles. Icicles also share some distinct qualities with glass: they are inanimate, they are translucent and they are brittle. Combined with the cold weather in the spring term in Buffalo, NY, ice was an affordable and accessible substitute material for the students to use to investigate the research question further. Similar to the process of ice formation, the project utilizes material-specific processes to yield variety and differentiation, in this case by looking at the age-old technique of kiln-formed glass in a mold. Instead of designing a precise form, this project develops a glass-specific fabrication process that generates forms that are geometrically different but typologically identical. In a second step, students investigated how these non-identical elements could be clustered through an aggregation logic that allows for high tolerance similar to Velcro surfaces that stick together without the need for precise placement. First tests with ice sintering produced agglomerations of icicles that were branchy and triggered thinking 

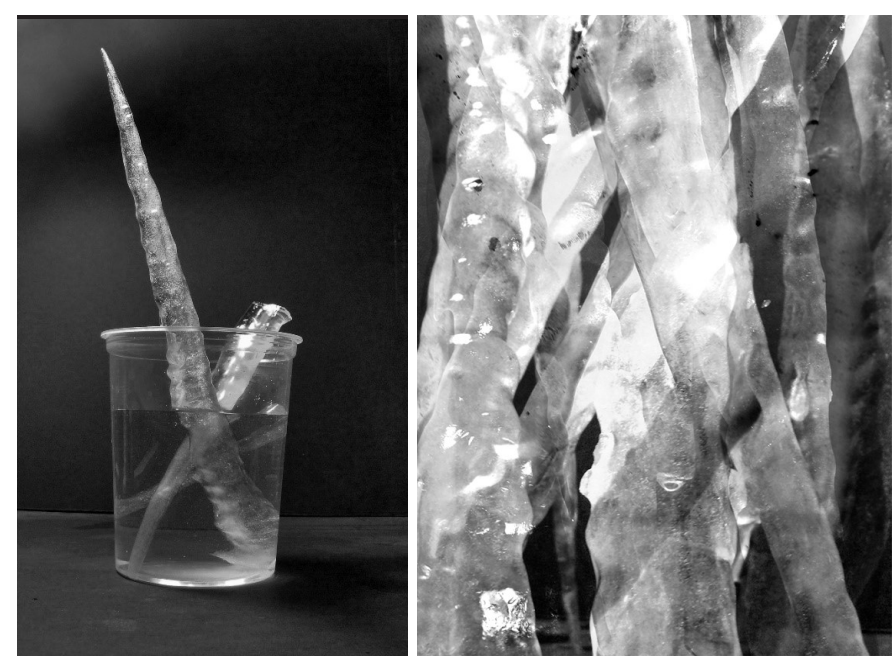

Figure 1: Sintering of Icicles (Image: Steve Smigielski)

about modules that could start interlocking in a similar manner to the anti-tank barrier known as Czech Hedgehog.

Sintering is the process of creating a singular solid from several parts through heat or pressure without reaching the melting point of the material (Hobbs and Mason [1]). The students learned to produce branchy modules that where all geometrically different while at the same time belonging to the same family of forms. The modules also demonstrated the ability to interlock in unexpected and seemingly random ways. The idea of aggregating non-identical modules into larger, stable assemblies was then tested with branch knots. Tests demonstrated that as the respective branches pointed in opposite directions, the aggregated mount became higher.

In a next test, students investigated the potential of scaling. Similar to the investigations by Eiichi Matusda under the direction of Michael Hensel and Achim Menges, the students dropped modules on top of each other as an aggregation method (Matusda et al. [2]). But in contrast to Matusda different scaled modules were poured on top of

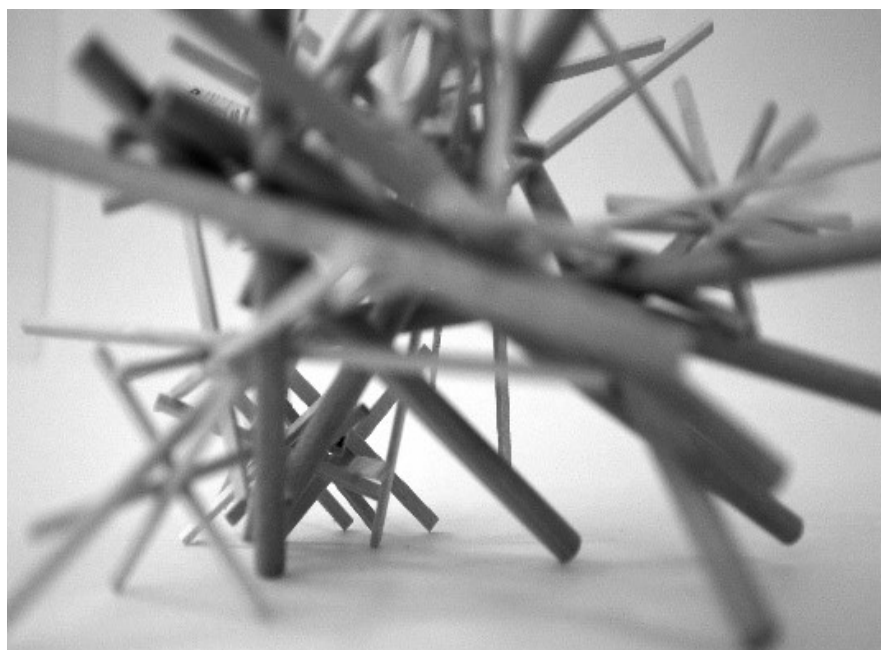

Figure 2: Scaling of identical modules creates spatial pockets. (Image: Steve Smigielski) each other. This test produced interesting spatial pockets, without the need for formwork to create enclosed space. Scaling addressed not only the structural aggregation of modules but also the creation of space. The knowledge gained from these preliminary tests was then combined and introduced into glass-making process which involved:

- devising a fabrication process that creates a family of related forms instead of a fixed form;

- using an assistive mold similar to the icicle cup instead of a mold that fully enforces its shape onto the cast;

- using a hierarchy of radically different scales to create larger aggregations and inherent spatial pockets;

The students used glass rods and started with simple bisque cups for the assistive mold. Because the mold had a circular section, it was difficult to place it into the kiln without moving the glass rods into an all-parallel bundle. As the glass rods tended to cluster in an allparallel bundle in the round cup mold, different mold geometries were then tested. The students proposed a hexagonal mold into which the glass rods were tossed. This mold geometry produced a wider variety of fused glass clusters and could be moved without changing the arrangement.

As the glass tacking temperature is higher than the slumping temperature, the sintering outcomes were very different from the earlier ice studies, producing droopy forms with bent branches that
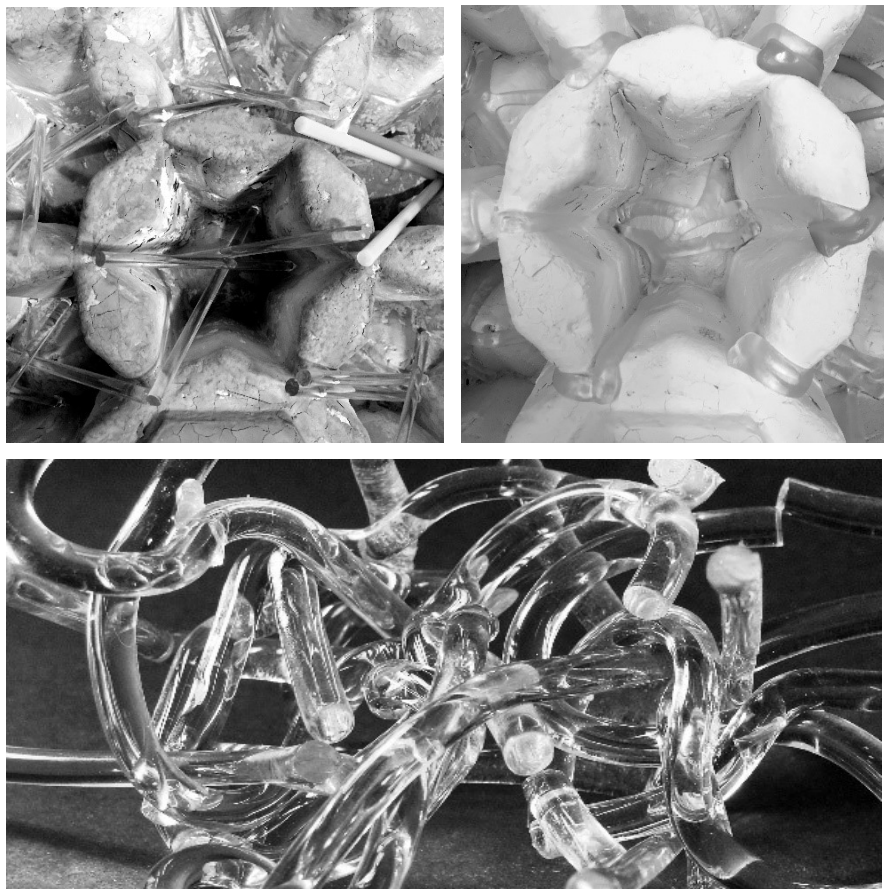

Figure 3: Assistive mold before and after firing (top). Aggregation of irregular modules shown at bottom image. (Images top: Steve Smigielski, Image to the bottom: Georg Rafailidis)

aided the aggregation process, similar to Velcro surfaces. To scale-up this approach to an architectural scale, two additional materials were 
Winter

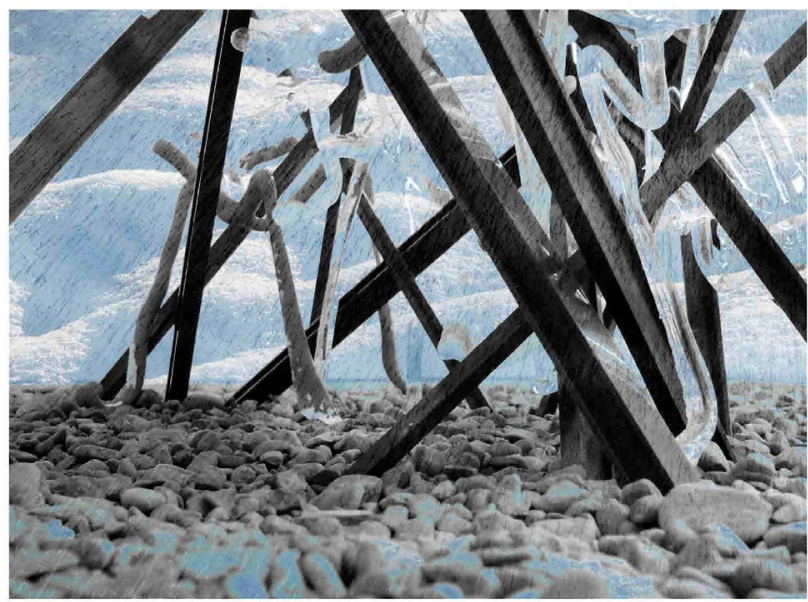

Spring

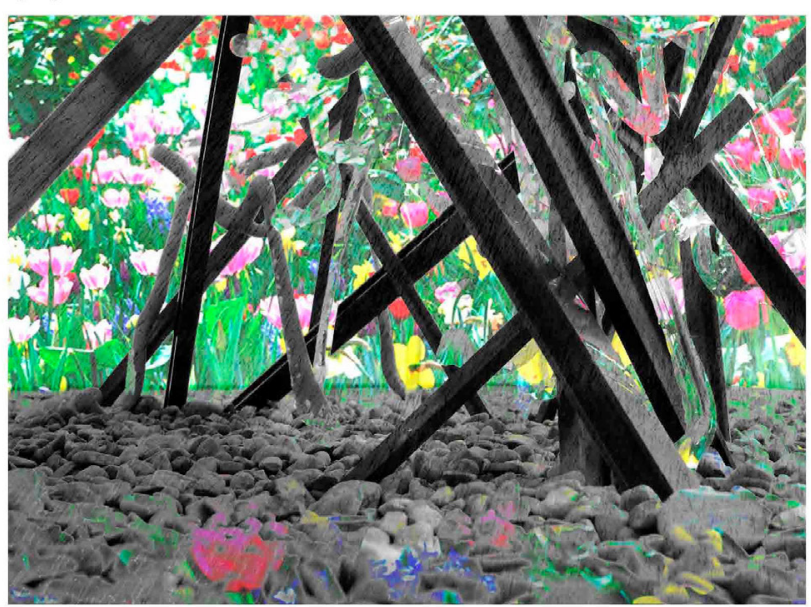

Figure 4: Self assembling spatial proposals with varying seasonal envelopes (Images: Kim Sass, Steve Smigielski)

introduced. Modules over $2 \mathrm{ft}$. were made of wood and modules over $8 \mathrm{ft}$. were made of steel. The construction sequence followed the hierarchy of scales and materials. In the documented model, first, three steel modules with a diameter of $30 \mathrm{ft}$. are dropped on top of one another. Next, wood modules with an $8 \mathrm{ft}$. diameter are dropped onto the assembly. The third pour consists of glass modules with diameters ranging from $2 \mathrm{ft}$. down to 4 in. , creating an outer crust. In contrast to standard constructions, this assembly does not require labor skills, is rapid and needs no fasteners. It is nearly self-assembling. In winter, snow and ice contribute to making a sealed envelope. In summer, growing vines provide shading. Each assembly/pour creates a geometrically different but typologically related structure. The assembly has no required tolerances.

\section{MONOLITHIC GLASS STRUCTURE THROUGH ELECTRIC ARC WELDING (STUDENT TEAM: TARAS KES, ANDREW KIM)}

While most projects took glass in various forms, and investigated techniques and formal outcomes of glass forming, the second project documented here investigates the architectural potential of glass making, turning sand or silicon dioxide into a range of vitreous or glassy substances using both the kiln and electric arc welding. This

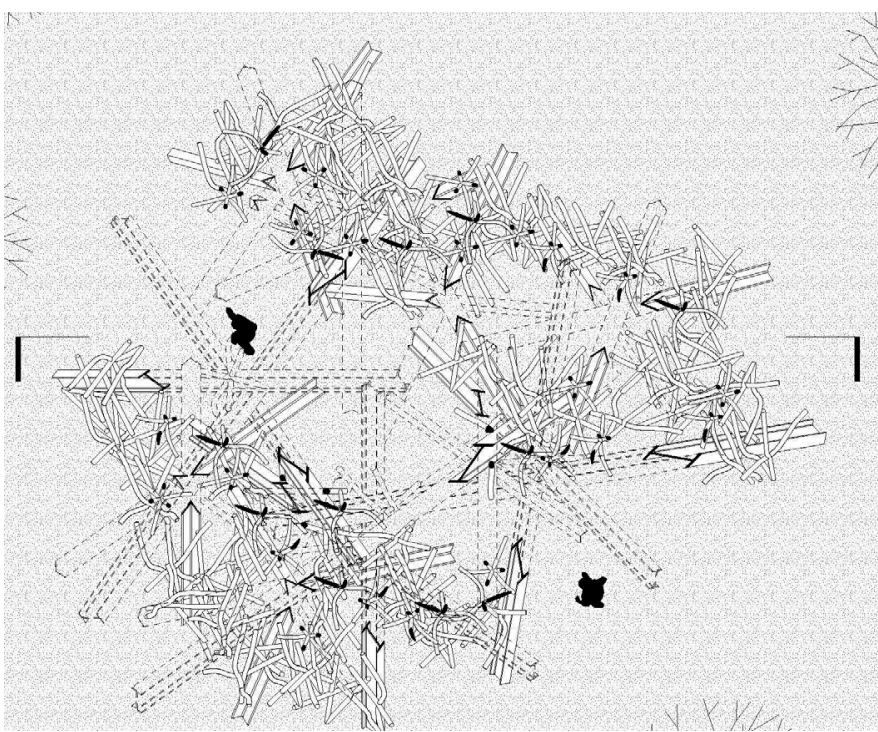

Figure 5: Plan (Drawing: Kim Sass, Steve Smigielski)

type of electric arc furnace was documented in depth by the French chemist Henri Moissan in 1904 (Moissan [3]). Students worked with silicon dioxide or silica, rather than glass, and experimented with various additives including soda ash and lime stone to lower the melting temperature of the sandy mixture, and to save energy. Initial experiments were conducted in a plywood "sandbox" using graphite rods in an electric arc welding process. The electric arc welder can produce temperatures up to 6500 degrees $F$ (approximately 3600 degrees $C$ ), which is well above the melting temperature of sand. First tests resulted in fulgurites, small pods characterized by a vitreous interior and a chimney much like those created by lightning found in nature.

In an architectural context, this process opens-up a series of glassspecific potentials and questions:

- Glass making is slow due in-part to long annealing times. Glass making with an electric arc is instant. Are there techniques that make

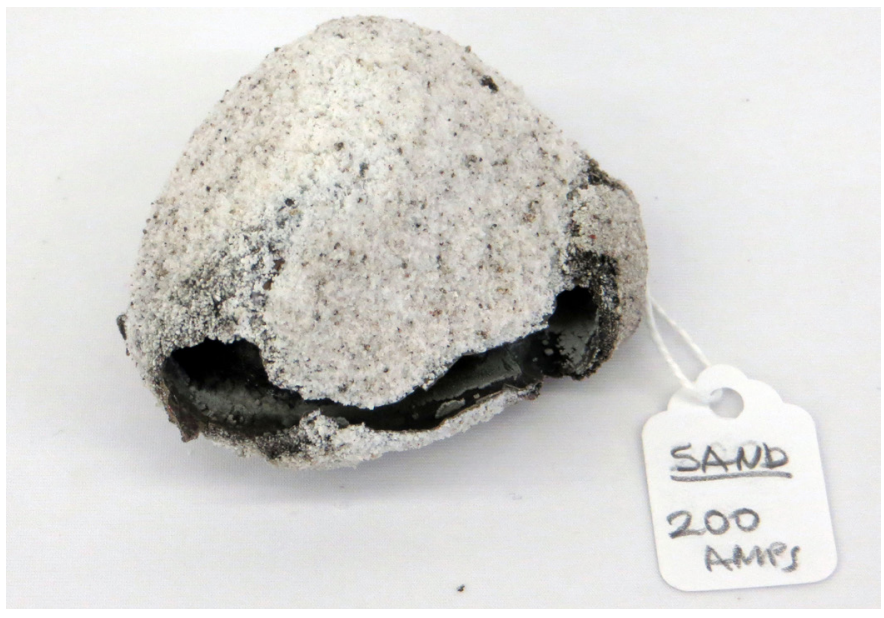

Figure 6: Typical electric arc fulgurite. (Image: Taras Kes, Andrew Kim) 
stable glass artifacts through this process that could eliminate the process of annealing?

- Glass making happens in large industrial settings. Could the electric arc technique allow for localized, low-tech, onsite production?

- Glass elements are typically connected through cold forming techniques like gluing. Could the electric arc allow for glass to be used as an adhesive, creating truly monolithic glass structures?

- Glass could be produced where sand is, avoiding the transport of the raw mate-rial and allowing the monolithic structures to disintegrate back into the natural setting after their use.

The initial experiments investigated different material mixes and used both the glass and ceramic kilns as well as the electric arc for heat sources. Results from the electric arc process consistently produced dark, smooth vitreous bodies encased in sandy shells (fulgurites), whereas kiln-based processes managed to fuse the sand into solid, crumbly swatches, but didn't transform the material visibly into a glassy, vitreous body.

The students continued by conducting experiments into how to modify the shape of the initial, typical fulgurite pod or egg. Tests demonstrated that when the electrodes were close to the sand surface, the hot gasses form a chimney to the sand surface where the gases escape. By placing the electrodes further down in the sandbox, egg shapes or pods are formed with two openings which connect to the graphite rods conducting the electrodes. Tests also demonstrated that the electrodes can be moved after fulgurites are made, to create interconnected, longer, vitreous artifacts. The graphite rods were used together with steel tools to pry-open the fulgurites when their glassy interiors were still molten; the results were patches of dark, multicolored glass with a sandy, crusty under-side. The electric arc was also used to weld these glass patches or pieces together with-out any added material, creating monolithic glass artifacts. Further tests investigated how pre-formed glass pieces could be attached, like glass marbles or glass rods.

The electric arc proved to be a suitable tool to form glass instantly in small batches from raw materials. How could one think of creating

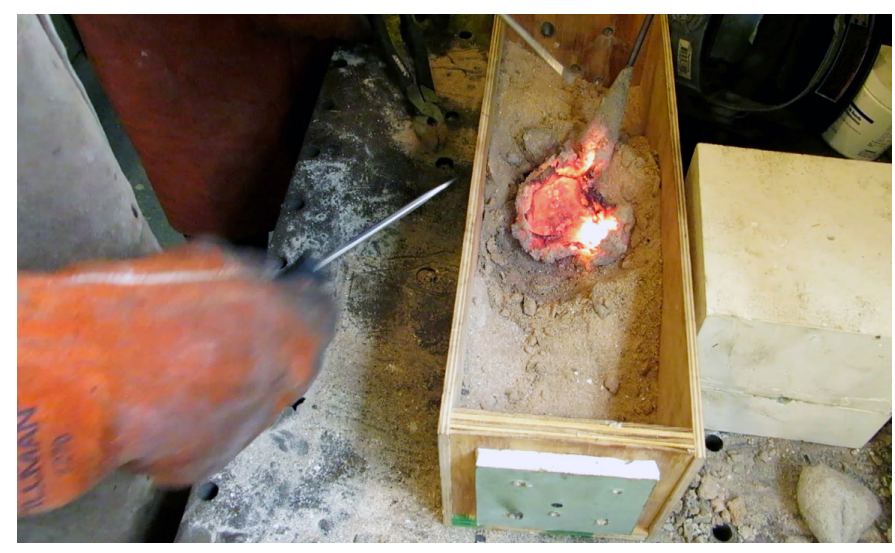

Figure 7: Fusing of glass fulgurites through the proposed electric arc method. (Image: Taras Kes, Andrew Kim) architectural form from this specific glass fabrication process? If used for fabrication in areas where sand is already naturally occurring (coastal areas, deserts), then it might be helpful to think of sand also as a formwork material to stay true to a pure, monolithic glass concept of construction. Students conducted test to see what forms sand adopts when it accumulates through pouring. When centrically poured, cones form. The angle of the cones vary depending on the humidity of the sand. Dry sand form cones with 30 -degree angles. Wet send can generate sand with steeper angles, up to 50-degrees. Electric arc fulgurites can be formed underneath the existing sand surface, withdrawn, pried open, and placed upon the formed sand cones that act as formwork. The glass artifacts would then be welded together through electric welding, forming a monolithic structure that consists of the same material as the surrounding natural environment. By digging out the interior sand, the glass shell remains. Damages to the structure could be repaired using the electric arc technique with the available material onsite. The structure could be demolished onsite by simply breaking it into smaller particles and mixing it back into the sur-rounding sand. Glass has an exceptionally long life span. When not mixed with other material, glass can retain this long material lifespan of thousands of years.

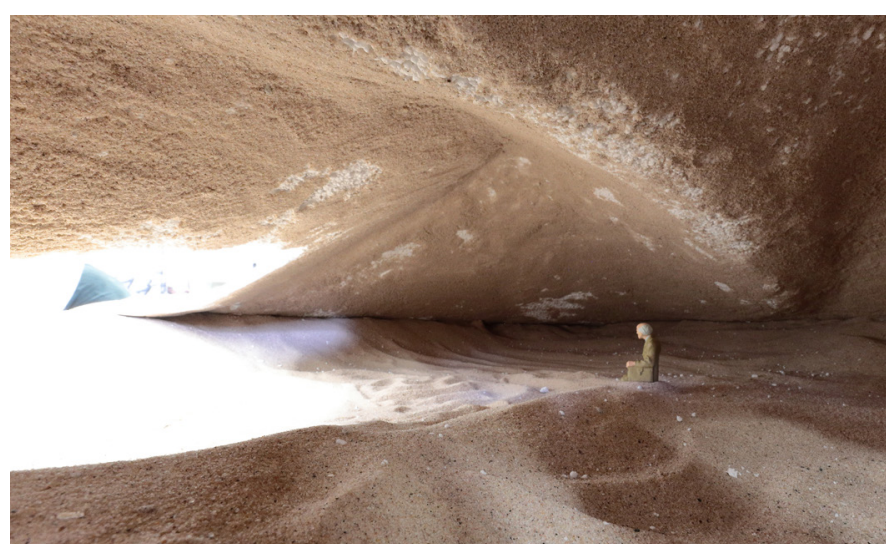

Figure 8: Spatial proposal for a monolithic glass structure. (Images: Georg Rafailidis)

\section{WOOD MOLD AS GLASS JOINT (STUDENT TEAM: KYLE MCMINDES, MATT MEYERS)}

The final project documented in this paper is one of the many blow-glass prototypes fabricated for us by the skilled glassblowers and gaffers at the Corning Museum of Glass in Corning, NY. For two years, staff of the Hot Glass Programs at CMoG have worked with us, reviewing drawings throughout the semester, and then fabricating select pieces using molds made with fruit wood, constructed by students. Unlike projects that used the glass kiln, to which students had daily access, projects that involved blown glass prototypes weren't subject to a process of experimentation and trial-and-error through the semester. The experience nevertheless yielded unexpected results that students could extrapolate on through drawings. The project shown here takes both the remains of fruitwood molds and the blown glass components both as part of a structural assembly. Molds - not 


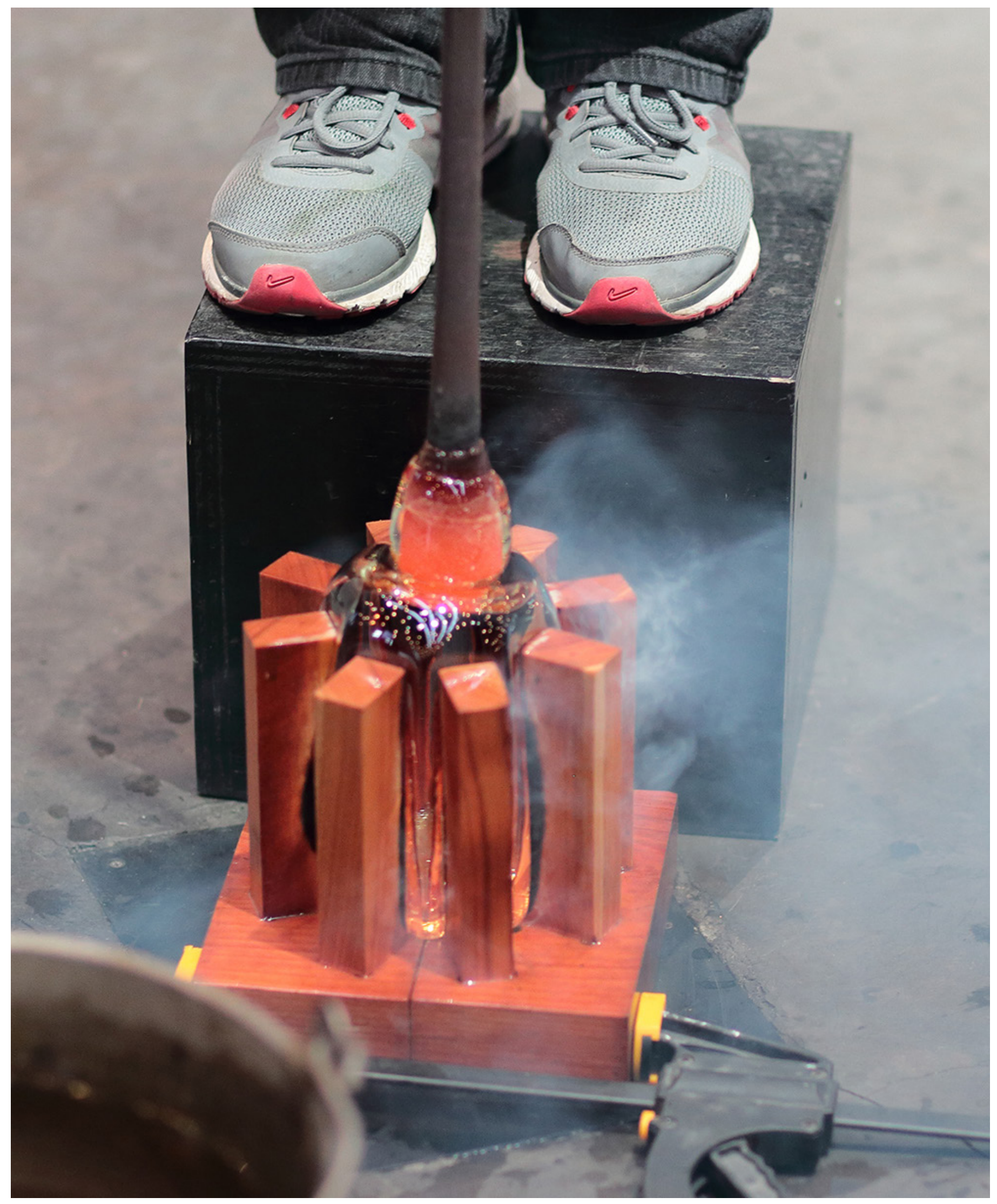

Figure 9: Hot glass prototyping of the glass block with respective wood mold/joint at the GlassLab of the Corning Museum of Glass. The wood strips of the mold are used as joints between the six blown glass artifacts. (Image: Georg Rafailidis) 
just in glass fabrication, but more widely in many fabrication processes - are often left as the invisible template that defines a form. They might be kept in an archive for further form-reproduction, or, if damaged or "exhausted" after several castings, are often tossed away. This project takes advantage of the fact that a fruitwood mold, in glass blowing, exhausts after, on average, 6-5 glass units are blown. The simple design of the mold allows it to be disassembled into a number of sticks that can be used to form wood joints in a ridged, bulbous glass block assembly. Because the glass is formed directly against the wood, the pieces of wood fit perfectly in the notches of the ridged glass units. Joints, in an all-glass assembly, are an issue because of the hardness and fragility of glass; wood, in contrast, is softer, is more flexible and able to absorb structural stresses. Fruitwood molds, in glassblowing, if they are made out of several pieces, have to be connected mechanically. The fact that the mold is constructed using mechanical fasteners (the sticks are screwed on a baseplate) also makes the disassembly of the mold quick and easy, without causing damage or change to the wood members. The wood joints would offer a number of opportunities in how to use and configure the glass assembly - the assembly could be tied-into a wood primary structure, for example. The combination of the "scrap" pieces of mold wood become an asset in an otherwise very formal and rigid type of construction (glass), enabling a glass construction to be created more flexibly and casually as a wood construction. It also questions the necessity for a material hierarchy in fabrication techniques, in which many fine, re-usable materials are needlessly tossed to produce a certain "finished" object or product.

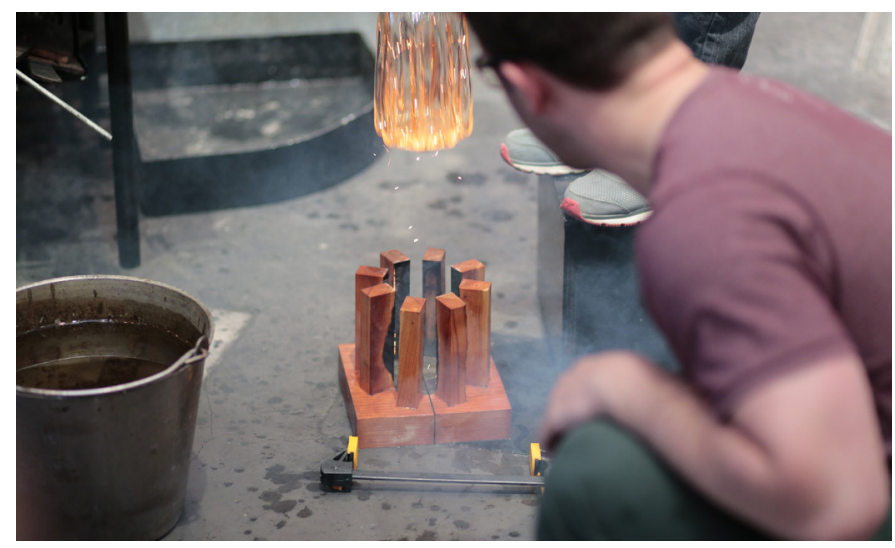

Figure 10: Hot glass prototyping of the glass block. (Image: Georg Rafailidis)

\section{CONCLUSION}

An fascination with the seeming inaccessibility of glass as a material for architectural experimentation lead to two years of working with students and glass through a range of techniques, including kiln-formed warm glass, the elemental process of glass making with sand and high heat, and glass blowing with wood molds, at the prestigious Corning Museum of Glass. The original motivation for this experimentation and collaboration was the design of our "Thermometric Façade" unit - a temperature-responsive glass-block unit filled with wax PCM, whose performance relies on an extremely precise interior cavity. Through handling glass and witnessing its behaviors and potentials first-hand through two architectural design studios, we can begin to imagine ways of generating a glass block prototype, a long-awaited proofof-concept with architecturally true materials. The experiments and design proposals that came out of the glass studios nevertheless stand on their own as design research into a new paradigm for architectural glass as a highly plastic, tactile, elemental and three dimensional material in architecture. In architecture glass is typically used for being invisible and flat. Architectural glass either disappears through transparency or by reflection. It is typically not considered suitable as a structural element and is regarded as an energetic "problem" due to low insulation values. The documented projects question these architectural preconceptions. The rich history of glass fabrication and glass components, as well as contemporary material developments suggest alternative readings of glass, as a material with a much more maleable and variable materiality than generally thought.

\section{ENDNOTES}

1. Hobbs, P.V; Mason, B.J.: Sintering+Adhesion of Ice. In: Philosophical Magazi-ne. Vol. 9, 1964, pp $181-197$.

2. Matusda, E.; Hensel, M.; Menges A.: Aggregat Gefertigter Partikel 01. In: ARCH+. Vol. 188, 2008, pp 80-81.

3. Moissan, H.: The Electric Furnace. Easton, PA: The Chemical Publishing Com-pany, 1904. 